\section{Urologia \\ Internationalis}

\section{Onkar Singh \\ Shilpi Singh Gupta Nand Kishore Arvind}

Department of Urology, Bhopal Memorial Hospital and Research Centre, Bhopal, India

\title{
Anterior Urethral Strictures: A Brief Review of the Current Surgical Treatment
}

\section{Key Words}

Urethra · Stricture - Urethroplasty · Anastomosis • Reconstruction

\begin{abstract}
A review of the recent literature on the surgical management of anterior urethral stricture was performed. The literature was searched via PubMed using the search terms 'urethral stricture' and 'urethroplasty' from 1996 to 2009. The management of anterior urethral strictures is changing rapidly in the sense that the reconstructive procedures have evolved greatly. Penile skin, because of its location and because it is hairless, has been popular and used for a long time. Since the early 1990s, buccal mucosa graft (BMG) was introduced in urethral reconstructive surgery and has become the first choice of most practicing urologists. Recently, there has been an increase in the use of lingual mucosa graft with various doctors reporting easy harvesting and lesser morbidity in comparison to BMG. Also, fibrin glue has recently been used to fix the graft with promising results. With the success of tissue-engineered materials that are still in the experimental phase, the urologist would no longer be limited by the quantity of the graft. These substitutes will also boost the appealing scarless endoscopic urethroplasty. This article provides a brief up-to-date review of the main surgical techniques in the management of anterior urethral stricture disease for the contemporary practicing urologists. Present
\end{abstract}

controversies have been given special emphasis. The possible future techniques and the future of the anterior urethral stricture surgery are also discussed in brief.

Copyright $\odot 2010$ S. Karger AG, Basel

\section{Introduction}

Urethral strictures are a common source of referrals to urologists. Anterior urethra classically is divided into bulbar and penile parts. Bulbar urethra is enclosed by the bulbospongiosus muscle. The penile urethra runs from the distal margin of the bulbospongiosus to the fossa navicularis and external meatus. Strictures of the bulbar urethra are commoner than those of the penile urethra [1]. Blunt perineal trauma, urethral catheterization or instrumentation, lichen sclerosus (LS) and sexually transmitted diseases are the most frequent causes of strictures. Surgical treatment of urethral stricture diseases is rapidly evolving. Currently there exist various means of reconstructing the urethra that are almost all comparable in terms of technical ease, associated morbidity and the outcome. But which one is the best technique has not yet been clearly defined [2]. In this period of rapid evolution of urethral reconstruction surgery, the contemporary urologists have to be up-to-date with the use of different surgical techniques and experimental advances. This article aims to provide an update on the reconstructive

\section{KARGER}

Fax +41613061234 E-Mail karger@karger.ch www.karger.com

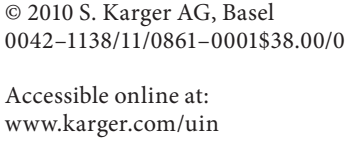

Dr. Onkar Singh

VPO Sangowa

Tehsil Nakoda

District Jalandhar, Punjab 144041 (India)

Tel. +91 98937 77321, E-Mail dronkarsingh@gmail.com 
techniques currently used to repair anterior urethral strictures, and provides a brief discussion of the current controversies related to this topic, possible future advancements and techniques.

\section{Methods}

The literature search was made with the PubMed database using the search terms 'urethral stricture' and 'urethroplasty' from 1996 to 2009. Only English language original and review articles were included presenting data regarding all aspects of the surgical repair of anterior urethral strictures. Articles presenting opinions rather than evidence and those published in non-peer-reviewed journals were not included. The relevance of the each search article to the subject matter was independently assessed by the authors. Meta-analyses or multivariate designs were not employed.

\section{Treatment of Anterior Urethral Stricture}

Treatment options for anterior urethral strictures include simple dilatation, urethrotomy, and various urethral reconstructive techniques. The choice of the particular operation depends on the site, length and the underlying pathology of the stricture, and any previous surgery [3]. For example, optical urethrotomy is more successful for strictures of the bulbar urethra than those of pendulous urethra because of more abundance of corpus spongiosum of the former. Further, the repairs in the penile urethra demand elasticity to bear the change in length of the penis during erection. This is the reason why local flaps are considered superior to grafts which are, nonetheless, still used with caution. Similarly, primary anastomosis is successful for the bulbar urethral strictures, but its use in the penile urethra is heralded by development of chordee with erection. It should also be emphasized that no one procedure is appropriate for all strictures [3].

\section{Urethral Dilatation}

This modality is used for treating localized and posturethroplasty urethral strictures. It is performed as a daycare procedure, and should also be considered in patients who are not willing to undergo a reconstructive procedure and/or not fit for anesthesia. But this procedure has a high recurrence rate and many patients will ultimately require repair [3].

\section{Direct Visual Internal Urethrotomy/Optical Urethrotomy}

This is performed using cold knife or laser as a daycare procedure. The stricture ring is incised at 12 o'clock. At the end of the procedure the patient is catheterized and the catheter is removed within $24-48 \mathrm{~h}$. Healing occurs by subsequent epithelialization of the constriction ring [4]. Self urethral calibration following direct visual internal urethrotomy (DVIU) has been shown to prolong the time to stricture recurrence [5]. Both of these procedures are ideal for short bulbar urethral strictures with no previous intervention. In such cases the success rate is up to $50 \%$ [4]. However, like dilatation, urethrotomy too has high recurrence rates. Moreover, repeated dilatation and DVIU render subsequent reconstructive surgery more difficult [3]. Further, surgical repair for patients with short urethral strictures is more cost-effective than repeated urethrotomy [6].

\section{Urethroplasty}

This is considered as the ideal treatment for anterior urethral strictures [7]. It can be offered to males of all age groups and can even be performed as a day procedure with costs comparable and even less than those of DVIU $[8,9]$. Different types of surgical procedures under this heading are listed below.

\section{End-to-End Anastomosis}

In general, strictures in the bulbar urethra of $2 \mathrm{~cm}$ or less are treated by excision and spatulated end-to-end anastomosis. In non-inflammatory strictures, this procedure can provide success rates of up to $95 \%$ [10]. Mundy [11] has recently illustrated the surgical technique of end-to-end anastomosis in his excellent paper. Eltahawy et al. [12] published their series of 260 patients with bulbar stricture who underwent end-to-end anastomosis over 10 years with a mean follow-up of 50.2 months. The mean stricture length was $1.9 \mathrm{~cm}$, and the authors described a success rate of $98.8 \%$. On the other hand, Gupta et al. [13] published the results of 114 patients who underwent end-to-end anastomosis in their center with a mean follow-up of 26.7 months and an average stricture length of $2.2 \mathrm{~cm}$. The success rate of the procedure was $82.6 \%$. While analyzing the long-term results of end-to-end anastomosis for bulbar urethral stricture of varied etiologies in 153 patients, Barbagli et al. [14] found that the procedure had a success rate of $90.8 \%$, 
and most patients felt satisfied with the surgical outcome despite some minor postoperative complications.

\section{Augmented Roof-Strip Anastomosis}

For longer strictures $(2-4 \mathrm{~cm})$ excisional augmented anastomotic urethroplasty which involves the segmental excision of the worst section of the stricture (but only up to $2 \mathrm{~cm}$ ) followed by reanastomosis of dorsally spatulated urethra and dorsal augmentation with a graft or flap is the most suitable [15]. This lowers the tension between the two mobilized ends of the urethra [11]. The half circumference of the urethra is then closed. Augmented roof strip anastomosis can also be performed with the graft or flap being placed on the ventral surface of urethra. Guralnick and Webster [15] have used this technique in 29 patients with bulbar urethral stricture. They use ventral onlay in 9 and dorsal onlay in 20 patients. The mean stricture length was $1.5 \mathrm{~cm}$ on retrograde urethrography and the mean excised length was $1.2 \mathrm{~cm}$. They reported a success rate of $93 \%$ at a mean follow-up of 28 months. Complications include new erectile dysfunction in 1 patient, postvoid dribbling in 13, pseudodiverticulum formation in 2 and subjective penile shortening in 5. Recently, $\mathrm{Ab}$ ouassaly and Angermeier [16] reported their experience of augmented anastomotic urethroplasty in 69 patients with a success rate of $90 \%$ at a mean follow-up of 34 months.

\section{Substitution Urethroplasty}

This is the most commonly practiced type of urethroplasty and it is the area of much progress in reconstructive urology. The primary indications for substitution urethroplasty, using local skin flaps or free grafts, are recurrent or long strictures of bulbar urethra $(>2 \mathrm{~cm})$ and those of penile urethra $(>1 \mathrm{~cm})$. The strictured urethral segment is either partly or wholly replaced with another tissue. An ideal replacement tissue is one that has a thick epithelial layer, minimal donor site complications, thin lamina propria, minimal shrinkage, is non-water absorbing, non-hair bearing and easy to procure [17]. Several autologous grafts or flaps from genital and extragenital skin or mucosa have been proposed for anterior urethral stricture repairs, but today substitution urethroplasty using BMG applied dorsally is the most popular and widespread method available to the urologists. $[3,18]$. The main reason for this is that this procedure can be easily performed and mastered. On the other hand, flap procurement while keeping its vascularity undisturbed requires great precision and experience. Different techniques of placing the graft have been described. The ure- thra is mobilized and the strictured segment is replaced with a graft placed dorsally or ventrally, either partly or wholly. Recently, Asopa et al. [19] described a technique of dorsal placement of a free full-thickness preputial graft or BMG without mobilizing the urethra. They did it by laying open the stricture ventrally and then incising the urethra dorsally to expose the tunica albuginea for placement of graft/flap followed by retubularization of the urethra. After a follow-up of 8-40 months, of 12 patients, only 1 recurred and required dilatation [19]. Kulkarni et al. [20] have described one-sided urethroplasty for anterior strictures to preserve the lateral vascularity of the urethra, which may be a slight but significant step toward perfecting the surgical technique of urethral reconstruction.

\section{Substitution Urethroplasty Using BMG}

BMG was first described in 1886 by Suprechko, and has become the most popular substitute material in the treatment of urethral strictures. It is readily available and easily harvested from the cheek or lip, allowing for a concealed donor site scar with low morbidity (all the qualities to make it a good choice of tissue), and has a thick elastinrich epithelium with natural resistance to infection and progression of other skin diseases such as LS $[3,21]$. Buccal mucosa is hairless, and the tough epithelium makes it tough yet easy to handle. It also has a thin and highly vascular lamina propria, which facilitates inoculation and imbibition and thus tissue harvesting. The donor site heals quickly with minimal morbidity and complications. Hence, since 1998 BMG has become the choice for urethral augmentation or reconstruction [3]. Furthermore, BMG grafts carried the highest success rate (96\%) of all free graft tissues or pedicled flaps used in singlestage bulbar urethroplasty stricture repair [17]. But it should be noted that almost all these series had a followup period of less than 10 years.

\section{Flap versus Graft}

This is an area of great controversy in this subject matter. Dubey et al. [22] performed a prospective randomized trial to compare outcomes of BMG dorsal onlay and penile skin flap dorsal onlay urethroplasty in patients with anterior urethral strictures, and found that on intermediate follow-up the success rate for BMG (89.9\%) and penile skin flap (85.6\%) was no different ( $p>0.05)$. But they also described the flap procedure as technically more complex, associated with higher morbidity and less preferred by patients when compared to the BMG procedure [22]. Recently, Whitson et al. [23] used penile skin 
flap urethroplasty for complex anterior urethral strictures and reported good and durable results. Success rates were $95,89,84$ and $79 \%$, at $1,3,5$ and 10 years, respectively. They also found smoking, a history of hypospadias repair and longer stricture length to be predictors of failure [23]. Barbagli et al. [24] reported their long-term results of dorsal onlay genital skin graft bulbar urethroplasty (12 ventral penile skin, 26 preputial mucosa), and found that the success rate drops mainly during first 5 years after which it is stable. Short, interim and long-term success rates among these patients were 90,73 and $66 \%$, respectively. They concluded that dorsal onlay skin graft urethroplasty is a valid alternative in patients who are not ideal candidates for BMG harvesting [24]. Pisapati et al. [25] have used BMG for anterior urethral strictures including those due to LS. They did it by using Asopa's ventral urethrotomy technique, without mobilizing the urethra, and recorded $87 \%$ overall success rate at a mean follow-up of 42 months [25]. Further, penile skin and BMG for anterior urethral stricture repair were compared in a single-center prospective study that found comparable results with both these grafts at 18 months of follow-up, but with extended follow-up, the use of penile skin seemed to be associated with a higher failure rate [26]. Buccal mucosa, although it has its own advantages related to easy harvesting and handling, is anyway a free graft. Thus, at present this controversy cannot be declared as resolved, and mandates further studies with long-term follow-up.

\section{Where Should the Graft/Flap Be Placed in Relation}

to the Urethra?

This has been another source of great controversy. Although Barbagli et al. [27] described 3 variations for BMG placement, ventral, dorsal and lateral, the first 2 are those which are most commonly done.

Dorsal placement of the graft has the advantage of using the corporal bodies to provide a secure well-vascularized graft bed that helps to prevent the protrusion of the graft with resulting pseudodiverticulum formation. In addition, this spread BMG fixation preserves graft width and hence urethral caliber [28]. On the other hand, ventral location provides the advantages of ease of exposure and good vascular supply by avoiding circumferential rotation of the urethra. Ventral urethrotomy allows the lumen to be clearly delineated, thus enabling the surgeon to identify mucosal edges, measure the size of the plate, carry out a watertight anastomosis and, if necessary, excise a portion of the stricture and perform dorsal reanastomosis [29-32].
Early success rates of dorsal and ventral onlay with BMG were 96 and 85\%, respectively. However, long-term follow-up revealed essentially no difference in success rates which in general have been high $[16,21,27,29,31$, 33-37]. Dorsal placement of BMG is currently considered the technique of choice with plenty of evidence supporting it [3, 18]. In 2001, Andrich et al. [21] compared their results of ventral onlay to dorsal onlay BMG bulbar urethroplasty. They followed 29 patients for 48-60 months with a success rate of $86 \%$. The rates of recurrent stricture were similar irrespective of the technique or graft material used. With both techniques, all patients had some postcoital pooling of semen or postmicturition urine dribbling, which was reported as significant in $21 \%$ of patient with ventral onlay grafts versus $17 \%$ of those with dorsal onlay grafts [21]. Kane et al. [35] reported a multicenter experience of 53 patients with complex bulbar urethral stricture treated by ventral onlay BMG urethroplasty, and followed for an average of 25 months with an overall success rate of $94.3 \%$. Four patients (7.5\%) had sacculation in the region of the graft but with good postoperative urine flow rates and minimal symptoms [35]. In 2003, Heinke et al. [31] published their results of 38 patients, of whom 30 had bulbar urethral disease treated by ventral onlay BMG urethroplasty. At a mean follow-up of 22.8 months, 7 of 38 patients had recurrence of their disease (18.4\%). Elliott et al. [38] reported the long-term results of the same procedure in 60 patients with bulbar urethral stricture with a $90 \%$ success rate at a mean follow-up of 47 months. Dubey et al. [39] in a series of $>100$ patients treated with various urethroplasty techniques reported data on 18 patients, of whom 7 had received ventral onlay BMG. Over a follow-up of 45.7 months, they reported a success rate of $77.8 \%$, but noted a significantly higher incidence of graft sacculation, diverticulum formation, urethrocutaneous fistula, and postmicturition dribbling than with dorsal onlay procedures. Stricture recurrence was equivalent among all groups [39]. Kellner et al. [32] in 2004 published the results of a long-term follow-up after ventral onlay BMG urethroplasty in 23 patients with anterior urethral strictures of varied etiologies. At mean follow-up of 50 months they reported a success (defined as normal voiding without any need for subsequent urethral manipulation) rate of $87 \%$ [32]. However, Berger et al. [40] reported their outcomes of management of posttraumatic urethral strictures. This included 7 patients undergoing ventral onlay BMG for bulbar urethral strictures. At a mean follow-up of 70.7 months, they noted a high failure rate of $57 \%$, with 4 of 7 patients requiring revision surgery [40]. Barbagli et al. 
[27] also compared success rates of bulbar urethroplasty using BMG at different locations and found no significant difference. Singh et al. [41] used dorsal placement of lingual mucosal graft (LMG) through Asopa's ventral sagittal urethrotomy approach, and showed the superiority of this technique over the classical Barbagli's procedure in terms of success and complications. Recently, McLaughlin et al. [42] reported their results of ventral placement of BMG in 58 patients with anterior urethral stricture and previous history of multiple surgeries. At a mean followup of 29.6 months, in 48 patients the success rate was $94 \%$. But Patterson and Chapple [43] reviewed the updated literature on the results of the use of BMG in dorsal onlay, ventral onlay, and tubularized grafts and the role of twostage procedures, to find out which technique is most appropriate. Although they found that in experienced hands the results of the ventral and dorsal onlay BMG for bulbar urethroplasty were equivalent, the dorsal onlay BMG was more suitable for surgeons new to the practice of urethroplasty. Further, the complications associated with the ventral onlay technique in series with longer follow-up tend to be more prevalent [43]. Most recently, Wang et al. [44] performed a meta-analysis review of the literature on dorsal or ventral graft urethroplasty. The success rates of ventral onlay urethroplasty (750 cases) and dorsal onlay (513 cases) were 82.5 and $86.9 \%(\mathrm{p}=0.034)$. Dorsal and ventral placement of the patch can also be combined for severe stricture disease. In 2008, Palminteri et al. [45] described the combined use of dorsal and ventral inlay of BMG in the management of severe bulbar urethral structuring. Through a ventral incision BMG is inlaid and quilted to the underlying corpora, followed by inlaying of another patch ventrally, and further augmentation of the urethra with spongiosus. They reported a success rate of $89.6 \%$ at a mean follow-up of 22 months, with 4 of 5 recurrences managed with DIVU alone with no further recurrence [45].

\section{The Other Graft Materials}

(1) Tunica vaginalis has been used to reconstruct bulbar urethral strictures with good success rates [46]. However, still more studies are needed to assess the suitability of this new graft. (2) Postauricular skin graft (PASG): Mundy and his group [47] in 1999 were the first to describe that it had results comparable to BMG owing to the presence of a dense subdermal plexus. PASG was used in patients with diseased genital skin or oral mucosa unsuitable for harvesting with a success rate of $89 \%$ [48]. But PASG is not popular. (3) LMG: This has recently emerged as a potential substitute for BMG. The site of graft har- vesting is the lateral mucosal lining of the tongue starting from a posterior landmark, and can be continued across the tip of the tongue to the other side if a longer graft is required. The graft harvesting site is simultaneously closed with a continuous running suture using 4-0 polyglactin suture for adequate homeostasis. Few studies exist in the literature which describe this procedure and the majority lack a long-term follow-up. Das et al. [49] achieved a success rate of $83.3 \%$ at 9 months' follow-up. Barbagli et al. [50] used LMG in 10 patients with anterior stricture and concluded that it may be the best alternative to BMG. Song et al. [51] in a good review of studies on urethroplasty using LMG concluded that easy harvesting and low morbidity can make LMG a suitable replacement for BMG.

\section{Urethral Strictures by Site}

In the anterior urethra, bulbar urethral strictures are more common than penile urethral strictures except in specialist units where penile strictures are becoming more common because of previous hypospadias surgery or LS [1]. On the whole, penile urethral surgery is technically more challenging than bulbar urethral surgery, and the results are less satisfactory [2]. Anastomotic urethroplasty provides best results for short (less than $2 \mathrm{~cm}$ long) congenital, traumatic or inflammatory strictures of the bulbar urethra. For longer strictures $(2-4 \mathrm{~cm})$ excisional augmented anastomotic urethroplasty is most suitable [15]. If a bulbar stricture is too long, which is often the case, circumferential urethral reconstruction with a patch (BMG or flap) is performed [21, 33, 52, 53]. It should be borne in mind that these stricture lengths are approximations and the choice of procedure is usually guided by intraoperative findings.

On the other hand, the use of BMG for one-stage reconstruction of meatal, penile and pan-urethral strictures has been limited [54]. The best management of the strictures of the penile urethra (not resulting from LS) appears to be with an onlay flap using penile skin [55]. A transverse flap of foreskin may be used in uncircumcised males to repair hypospadias. Flaps harvested from the prepuce and the shaft can be used to repair an up to 15-cm-long stricture. Excision of a tight segment before onlay is usually not recommended so as to avoid chordee $[6,47]$. However, the recurrence rates have been similar with the use of both BMG and penile skin flap urethroplasty for anterior urethral strictures $[23,39,56]$, but greater morbidity with the use of flaps was reported by Dubey et al. [39]. They further confirmed the versatility of BMG as urethral substitute by successfully using it for 
the entire anterior urethra in both one- and two-stage reconstructions [54]. However, as penile skin flap urethroplasty is a relatively difficult procedure to perform when compared to BMG urethroplasty, the outcome of flap procedures done by lesser experienced surgeons may have higher morbidity and recurrence or both than those done by surgeons with more expertise. The surgeons' experience is not generally taken into account while calculating the overall recurrence and morbidity rates, and this may lead to biased labelling of flap urethroplasty as a procedure with higher morbidity rate. It is actually a procedure that demands more expertise than BMG urethroplasty does. Further, Asopa et al. [19] and Gupta et al. [13] successfully used dorsal fixation of BMG for penile and combined bulbopenile and pan-urethral strictures, respectively. Levine et al. [57] evaluated 35 patients with bulbar and 18 with penile urethral stricture who were treated with BMG (dorsal or ventral) urethroplasty, and found good success rates in both groups.

\section{Single-Stage versus Staged Urethroplasty}

Single-stage urethroplasty for bulbar strictures using BMG has been reported to carry a very high success rate (96\%) [17]. Long-term (at least 5 years) success rates for single-stage BMG urethroplasty for repair of defects associated with hypospadias/epispadias and strictures were $84 \%$ [58] and 75\% [59], respectively.

Staged urethroplasty has been recommended for more complex strictures requiring extensive tissue replacement or in cases with adverse local conditions including extensive scarring, fistulization or infection [60]. Early reports of staged BMG repair exhibited a $93 \%$ success rate [60], and long-term data showed virtually the same rate. Dubey et al. [54] used a procedure in which the first stage included complete excision of stricture and the placement of BMG to form the urethral plate, and the second stage used a penile skin flap to form the urethra. They reported favorable results.

In 2003, Heinke et al. [31] reported that even complex and extensive urethral defects can be repaired in a single stage. Markiewicz et al. [61] in an excellent review of the literature on the use of BMG in urethroplasty found that the success rate in 18 studies (529 cases) that assessed single-stage BMG urethroplasty for stricture repair was $81.1 \%$. The success rate for 4 studies (165 cases) using two (or more)-stage BMG urethroplasty repair was $75.8 \%$ $(\mathrm{p}=0.149)$ [61]. Palminteri et al. [60] used only two-stage BMG urethroplasty for bulbar urethral stricture with a success rate of $93 \%$. While operating on a population with LS or with previously successful hypospadias/epispadias repair, Andrich et al. [62] reported a 50\% success rate using two-stage procedures which necessitated multiple subsequent repairs. They found that two-stage urethroplasty has a significantly lower restricture rate than single-stage urethroplasty for complex strictures in the penile urethra, but it does so at the expense of a significantly higher revision rate [62]. Both Palminteri et al. [60] and Andrich et al. [62] advised a two-stage approach only when adverse conditions like the one mentioned above were present. Further, the penile urethral strictures should undergo a single-stage procedure whenever possible to avoid patient discomfort and disability. This is usually possible for strictures caused by trauma, infection, instrumentation or catheters, when the penile shaft is on the whole normal and the urethral plate, corpus spongiosum and dartos fascia are suitable for single-stage reconstruction [18]. On the other hand, for strictures after hypospadias repair or where the penile skin, urethral plate and dartos fascia are not suitable for single-stage reconstruction, two-stage urethroplasty is recommended $[18,63]$.

\section{Strictures from LS}

The changes from LS most commonly occur in the glans penis and prepuce, causing phimosis. With more extensive involvement it can affect the urethra as far back as the midbulb [1]. Most of the patients with urethral involvement require complex reconstructive surgery procedures that can have high complication and failure rates of up to $71 \%$ [64]. Surgical management of the urethral involvement by LS is difficult, and ranges from extended simple meatotomy for distal strictures to complex staged repairs for more extensive disease. These usually include excision of the entire affected urethra and the use of BMG for reconstruction, so as to prevent recurrence of disease in the repaired area [1].

Dubey et al. [65] reported the outcomes of 39 patients with LS-related anterior urethral strictures that were treated by either single-stage dorsal onlay BMG urethroplasty (25 patients with a salvageable urethral plate) or two-stage urethroplasty (14 patients with severely scarred urethral plate). They assessed the outcomes in terms of cosmesis, stricture recurrence and complications. At a mean follow-up of 32.5 months 3 patients (12\%) treated in a single stage had recurrent strictures, which were treated with urethroscopic interventions. All patients had a normal meatus and none had chordee or erectile dysfunction. Among those treated in two stages, 4 (28.6\%) required stomal revision and 2 had glans cleft narrowing after the first stage. Following stage two, 3 patients had 
recurrent stricture, 2 of whom were treated with optical urethrotomy and 1 underwent repeat urethroplasty. The authors concluded that with a viable urethral plate singlestage dorsal onlay BMG urethroplasty provides excellent intermediate term results for LS-related strictures [65]. Two-stage procedures have been advocated whenever the urethral plate appears unsalvageable [54]. Trivedi et al. [66], from their experience of using genital and nongenital skin in 153 patients of anterior urethral stricture related to LS, recommended that single-stage substitution urethroplasty using nongenital skin as a free graft is the best. While evaluating the impact of LS on the outcome of BMG urethroplasty in the management of anterior urethral strictures, Levine et al. [57] stressed the importance of complete excision of the diseased urethra with multistage repair, and reported a higher rate of stricture recurrence with single-stage repair. Kulkarni et al. [67] in their multicenter international experience with 215 male patients of LS of the genitalia and urethra found that the use of one-stage oral graft urethroplasty has greater success than the staged procedures. Furthermore, in an attempt to decrease the morbidity, some workers prefer perineal urethrostomy as an alternative to complex staged repairs, especially in the older patients $[3,68]$.

Further, Dubey et al. [54] advocated preferential use of several BMGs in single stage while managing longer strictures particularly those related to LS. Harvesting BMG from several sites has not been found to cause significant morbidity in the long term, and taking grafts from both cheeks and the lower lip, they were able to reconstruct urethral lengths even up to $17 \mathrm{~cm}$. However, whenever there is not enough BMG to substitute the entire length of the stricture, they recommended the combined use of BMG and a penile skin flap [54].

Thus, it is clear that now the trends have moved towards using single-stage repair for difficult strictures of anterior urethra due to LS, and the substitute of choice is BMG.

\section{Obliterative Strictures}

In the literature, little or no differentiation has been made among urethroplasties for the strictures with the lumen more or less completely obliterated, and those where the lumen is significantly narrowed but not actually lost [2]. Thus there is no gold standard for the treatment of long anterior urethral strictures that are more or less obliterative [2]. Standard patch urethroplasties may not be able to deal adequately with such strictures. The BMG-augmented roof-top anastomosis is useful when the obliterated segment is short and forms part of a long stricture in which the lumen is otherwise okay [2]. But when the whole stricture is more or less obliterative throughout its length, long flap repair preferably using a patch of penile shaft skin is a good option [69]. In cases of strictures complicated by periurethral infection or abscess, a two-stage repair is preferred. The first stage involves marsupialization of the skin to the margins of a full-length ventral urethrotomy followed by mobilization and rolling-up of a neourethral strip ( $3 \mathrm{~cm}$ wide) into a tube in the second stage [2].

\section{Role of Fibrin Glue}

Fibrin glue increases tissue plane adherence, accelerates revascularization, reduces hemorrhage, prevents seroma formation and decreases inflammation [18]. In 2004, Hick and Morey [70] used fibrin in anterior urethral reconstruction in 25 patients (mean stricture length $8.3 \mathrm{~cm}$ ) and compared their outcome with that of $18 \mathrm{pa}-$ tients (mean stricture length $7.24 \mathrm{~cm}$ ) in whom fibrin was not used. All procedures were performed by same surgeon (Morey). They found that the use fibrin glue promotes early catheter removal and enhances wound healing after penile urethral reconstruction. Barbagli et al. [71] reported in 2006 their first series of 6 patients of dorsal onlay BMG urethroplasty with fibrin glue to support the graft on the corporal bodies. Short-term results were promising with no restrictures at 12 months. However, further comparative studies are required to confirm that the use of fibrin glue is really beneficial and to evaluate whether its use reduces restenosis rate following substitution urethroplasty [72].

\section{Tissue-Engineering Urethroplasty}

Every autologous tissue is associated with donor site morbidity, time-consuming harvesting, and morphologic features that may cause complications or restrictures. Thus urethral tissue engineering is a new emerging field. At present there is little data available for tissue-engineered urethroplasty in humans. Various heterologous materials have been used but with bad results in the long term [73]. The main problem is the development of a suitable carrier for cells. Advancements in this field have made it possible for scientists to be able to regenerate urethral tissues using biodegradable organic matrices. Carson [74] suggested that the use of tissue engineering to optimize graft material may allow us to combine the most refined surgical techniques with the best graft material, to achieve even more reliable results. Palminteri et al. [75] performed urethroplasty in 20 patients using collagen tissue matrix manufactured from porcine small intestinal 
submucosa. For anterior urethral strictures a success rate of $85 \%$ was found at 21 months. El Kassaby et al. [76] recently described an 'off-the-shelf' collagen matrix based on cultured human cadaveric bladder mucosa that showed promising results. Later, they performed a randomized comparative study between the use of this material and BMG in complex anterior urethral strictures, and found significant improvement in postoperative urine flow in both the groups [77]. Bhargava et al. [78] in 2008 reported the clinical outcome of the first human series (5 patients) in which autologous tissue-engineered buccal mucosa was used in substitution urethroplasty. All 5 patients had strictures related to LS. Two out of the 5 patients developed asymptomatic recurrence of stricture within 1 year that was detected on urethroscopy. This occurred as a result of graft fibrosis that as indicated by the authors might be in part attributed to the underlying disease.

\section{Endoscopic Urethroplasty}

This may be an option for complex or recurrent strictures where urethrotomy alone is inadequate. This procedure involves preparation of a free graft, endoscopic delivery and fixation in the stricture bed with the help of balloon catheters [79]. Endoscopic urethroplasty has not gained wide acceptance and the number of studies is limited. Recently, Farahat et al. [80] performed endoscopic urethroplasty using a small intestinal submucosa patch in 10 patients with short urethral stricture that was associated with mild spongiofibrosis, and achieved $80 \%$ success at 12-18 months' follow-up.

\section{The Future of Anterior Urethral Stricture Surgery}

There are two important fields that seem to guide the future trends in the management of anterior urethral stricture disease: tissue-engineering substitutes and endoscopic reconstruction. BMG, which is considered the best substitute for urethral tissue at present, can be cultured and seeded to a scaffold for urethral replacement [81]. This will avoid the need for tissue transfer in patients with long and complex strictures. Moreover, the quantity or quality of urethral substitutes available in any given patient will not be a problem. Progress in and acceptance of artificial tissue replacements, allografts and xenografts, thus obviating the need for graft harvesting, could be easily anticipated [82]. Also, refinement in endoscopic instrumentation and techniques may enlarge the area of endoscopic urethroplasty. This may shift today's stan- dard surgical management to scarless urethral reconstruction. Further, the findings of a pilot study on the use of tissue-engineered buccal mucosa in substitution urethroplasty for LS-related strictures indicate future strategies for the management of such complex urethral strictures; it is the underlying stricture pathophysiology that should be given more concern rather than the availability of the graft [44]. Thus, future research should target this concern too.

\section{Conclusion}

In view of the fact that the surgical treatment of urethral stricture diseases is continually evolving, and that at present the choice of a procedure for a particular patient depends mainly on the expertise of the surgeon and the available resources, contemporary urosurgeons working in this field should keep themselves updated so as to obtain the best outcomes. Among various available reconstructive urethral procedures for urethral stricture disease, the superiority of one approach over another cannot be clearly stated. Still, single-stage dorsal BMG urethroplasty is currently considered the standard procedure. Unilateral urethroplasty represents a small but definitely significant step forward. Newer materials like engineered tissues that are expected to become the standard in future represent a platform for further studies. The technique of endoscopic urethroplasty combined with the use of engineered tissues also mandates further work.

References $\quad D_{1}$ Venn SN, Mundy AR: Urethroplasty for balanitis xerotica obliterans. Br J Urol 1998;81: $735-737$.

2 Andrich DE, Mundy AR: What is the best technique for urethroplasty? Eur Urol 2008; 54:1031-1041.

73 Peterson AC, Webster GD: Management of urethral stricture disease: developing options for surgical intervention. BJU Int 2004; 94:971-976.

4 Pansadoro V, Emiliozzi P: Internal urethrotomy in the management of anterior urethral strictures: long-term follow up. J Urol 1996; 156:73-75.

5 Lauritzen M, Greis G, Sandberg A, Wedren H, Ojdeby G, Henningsohn L: Intermittent self-dilatation after internal urethrotomy for primary urethral strictures: a case-control study. Scand J Urol Nephrol 2009;43:220225 . 
66 Wright JL, Wessells $\mathrm{H}$, Nathens AB, Hollingworth W: What is the most cost effective treatment for 1 to 2 -cm bulbar urethral strictures: societal approach using decision analysis. Urology 2006;67:889-893.

7 Waxman SW, Morey AF: Management of urethral strictures. Lancet 2006;367:13791380.

$\checkmark 8$ MacDonald MF, Al-Qudah HS, Santucci RA: Minimal impact urethroplasty allows same-day surgery in most patients. Urology 2005;66:850-853.

$>9$ Rourke KF, Jordan GH: Primary urethral reconstruction: the cost minimized approach to the bulbous urethral stricture. J Urol 2005; 173:1206-1210.

10 Santucci RA, Mario LA, McAninch JW: Anastomotic urethroplasty for bulbar urethral strictures. Analysis of 168 patients. J Urol 2002;169:1715-1719.

11 Mundy AR: Anastomotic urethroplasty. BJU Int 2005;96:921-944.

-12 Eltahawy EA, Virasoro R, Schlossberg SM, McCammon KA, Jordan GH: Long-term followup for excision and primary anastomosis for anterior urethral strictures. J Urol 2007; 177:1803-1806.

-13 Gupta NP, Mishra S, Dogra PN, Hemal AK, Seth A, Kumar R: Outcome of end-to-end urethroplasty: single-center experience. Urol Int 2009;82:179-182.

- 14 Barbagli G, De Angelis M, Romano G, Lazzeri M: Long-term followup of bulbar end-to-end anastomosis: a retrospective analysis of 153 patients in a single center experience. J Urol 2007;178:2470-2473.

15 Guralnick ML, Webster GD: The augmented anastomotic urethroplasty: indications and outcome in 29 patients. J Urol 2001;165: 1496-1501.

-16 Abouassaly R, Angermeier KW: Augmented anastomotic urethroplasty. J Urol 2007;177: 2211-2216.

17 Wessells H, McAninch JW: Current controversies in anterior urethral stricture repair: free-graft versus pedicled skin-flap reconstruction. World J Urol 1998;16:175-180.

-18 Barbagli G, Lazzeri M: Surgical treatment of anterior urethral stricture diseases: brief overview. Int Braz J Urol 2007;33:461-469.

-19 Asopa HS, Garg M, Singhal GG, Singh L, Asopa J, Nischal A: Dorsal free graft urethroplasty for urethral stricture by ventral sagittal urethrotomy approach. Urology 2001;58:657-659.

-20 Kulkarni S, Barbagli, Sansalone S, Lazzeri M: One-sided anterior urethroplasty: a new dorsal onlay graft technique. BJU Int 2009; 104:1150-1155.

-21 Andrich DE, Leach CJ, Mundy AR: The Barbagli procedure gives the best results for patch urethroplasty of the bulbar urethra. BJU Int 2001;88:385-389.
22 Dubey D, Vijjan V, Kappor R, Srivastava A, Mandhani A, Kumar A, et al: Dorsal onlay buccal mucosa versus penile skin flap urethroplasty for anterior urethral strictures: results from a randomized prospective trial. J Urol 2007; 178:2466-2469.

23 Whitson JM, McAninch JW, Elliott SP, Alsikafi NF: Long-term efficacy of distal penile circular fasciocutaneous flaps for single stage reconstruction of complex anterior urethral stricture disease. J Urol 2008;179: 2259-2264.

24 Barbagli G, Morgia G, Lazzeri M: Dorsal onlay skin graft bulbar urethroplasty: longterm follow-up. Eur Urol 2008;53:628-633.

25 Pisapati VL, Paturi S, Bethu S, Jada S, Chilumu R, Devraj R, et al: Dorsal buccal mucosal graft urethroplasty for anterior urethral stricture by Asopa technique. Eur Urol 2009; 56:201-205.

26 Raber M, Naspro R, Scapaticci E, Salonia A, Scattoni V, Mazzoccoli B, et al: Dorsal onlay graft urethroplasty using penile skin or buccal mucosa for repair of bulbar urethral stricture: results of a prospective single center study. Eur Urol 2005;48:1013-1017.

27 Barbagli G, Palminteri E, Guazzoni G, Montorsi F, Turini D, Lazzeri M: Bulbar urethroplasty using buccal mucosa grafts placed on the ventral, dorsal or lateral surface of the urethra: are results affected by the surgical technique? J Urol 2005;174:955-957.

28 Iselin CE, Webster GD: Dorsal onlay graft urethroplasty for repair of bulbar urethral stricture. J Urol 1999;161:815-818.

$>29$ Wessells H: Ventral onlay graft techniques for urethroplasty. Urol Clin North Am 2002; 29:381-387.

30 Armenakas NA: Long-term outcome of ventral buccal mucosal grafts for anterior urethral strictures. AUA News 2004;9:1718.

-31 Heinke T, Gerharz EW, Bonfig R, Riedmiller $\mathrm{H}$ : Ventral onlay urethroplasty using buccal mucosa for complex stricture repair. Urology 2003;61:1004-1007.

-32 Kellner DS, Fracchia JA, Armenakas NA: Ventral onlay buccal mucosal grafts for anterior urethral strictures: long-term followup. J Urol 2004;171:726-729.

-33 Barbagli G, Selli C, Tosto A, Palminteri E: Dorsal free graft urethroplasty. J Urol 1996; 155:123-126.

34 Andrich DE, Mundy AR: Substitution urethroplasty with buccal mucosal-free grafts. J Urol 2001; 165:1131-1134.

35 Kane CJ, Tarman GJ, Summerton DJ, Buchmann CE, Ward JF, O'Reilly KJ, et al: Multi-institutional experience with buccal mucosa onlay urethroplasty for bulbar urethral reconstruction. J Urol 2002;167:13141317.

36 Pansadoro V, Emiliozzi P, Gaffi M, Scarpone P, DePaula F, Pizzo M: Buccal mucosa urethroplasty in the treatment of bulbar urethral strictures. Urology 2003;61:10081010 .
37 Pansadoro V, Emiliozzi P, Gaffi M, Scarpone P: Buccal mucosa urethroplasty for the treatment of bulbar urethral strictures. J Urol 1999;161:1501-1503.

38 Elliott SP, Metro MJ, McAninch JW: Longterm followup of the ventrally placed buccal mucosa onlay graft in bulbar urethral reconstruction. J Urol 2003;169:1754-1757.

39 Dubey D, Kumar A, Bansal P, Srivastava A, Kapoor R, Mandhani A, et al: Substitution urethroplasty for anterior urethral strictures: a critical appraisal of various techniques. BJU Int 2003;91:215-218.

40 Berger AP, Deibl M, Bartsch G, Steiner H, Varkarakis J, Gozzi C: A comparison of onstage procedures for post-traumatic urethral stricture repair. BJU Int 2005;95:1299-1302.

-41 Singh PB, Das SK, Kumar A, Sharma GK, Pandey AK, Swain S, et al: Dorsal onlay lingual mucosal graft urethroplasty: comparison of two techniques. Int J Urol 2008;15: 1002-1005.

$\checkmark 42$ McLaughlin MD, Thrasher JB, Celmer A, Bruegger D: Buccal mucosal urethroplasty in patients who had multiple previous procedures. Urology 2006;68:1156-1159.

43 Patterson JM, Chapple CR: Surgical techniques in substitution urethroplasty using buccal mucosa for the treatment of anterior urethral strictures. Eur Urol 2008;53:11621171.

-44 Wang K, Miao X, Wang L, Li H: Dorsal onlay versus ventral onlay urethroplasty for anterior urethral stricture: a meta-analysis. Urol Int 2009;83:342-348

45 Palminteri E, Manzoni G, Berdondini E, Di Fiore F, Testa G, Poluzzi M, et al: Combined dorsal plus ventral double buccal mucosa graft in bulbar urethral reconstruction. Eur Urol 2008;53:81-90.

-46 Foinquinos RC, Calado AA, Janio R, Griz A, Macedo A Jr, Ortiz V: The tunica vaginalis dorsal graft urethroplasty: initial experience. Int Braz J Urol 2007;33:523-529.

47 Greenwell TJ, Venn SN, Mundy AR: Changing practice in anterior urethroplasty. BJU Int 1999;83:631-635.

48 Manoj B, Sanjeev N, Pandurang PN, Jaideep M, Ravi M: Postauricular skin as an alternative to oral mucosa for anterior onlay graft urethroplasty: a preliminary experience in patients with oral mucosa changes. Urology 2009;74:345-348.

49 Das SK, Kumar A, Sharma GK, Pandey AK, Bansal H, Trivedi S, et al: Lingual mucosal graft urethroplasty for anterior urethral strictures. Urology 2009;73:105-108.

50 Barbagli G, De Angelis M, Romano G, Ciabatti PG, Lazzeri M: The use of lingual mucosal graft in adult anterior urethroplasty: surgical steps and short-term outcome. Eur Urol 2008;54:671-676.

51 Song LJ, Xu YM, Lazzeri M, Barbagli G: Lingual mucosal grafts for anterior urethroplasty: a review. BJU Int 2009;104:1052-1056. 
-52 Barbagli G, Selli C, di Cello V, Mottola A: A one-stage dorsal free-graft urethroplasty for bulbar urethral strictures. BJU 1996;78:929932.

-53 Iselin C, Webster G: Dorsal onlay urethroplasty for urethral stricture repair. World J Urol 1998;16:181-185.

54 Dubey D, Kumar A, Mandhani A, Srivastava A, Kapoor R, Bhandari M: Buccal mucosal urethroplasty: a versatile technique for all urethral segments. BJU Int 2005;95:625-629.

-55 Morey AF, Pace PC, McAninch JW: Failed anterior urethroplasty: guidelines for reconstruction. J Urol 1997;158:1383-1387.

-56 McAninch JW, Morey AF: Penile circular fasciocutaneous skin flap in 1-stage reconstruction of complex anterior urethral stric tures. J Urol 1998;159:1209-1213.

57 Levine LA, Strom KH, Lux MM: Buccal mucosa graft urethroplasty for anterior urethral stricture repair: evaluation of the impact of stricture location and lichen sclerosus on surgical outcome. J Urol 2007;178:20112015.

58 Fichtner J, Filipas D, Fisch M, Hohenfellner R, Thuroff JW: Long-term followup of buccal mucosa onlay graft for hypospadias repair: analysis of complications. J Urol 2004;172: 1970-1972.

59 Fichtner J, Filipas D, Fisch M, Hohenfellner $\mathrm{R}$, Thuroff JW: Long-term outcome of ventral buccal mucosa onlay graft urethroplasty for urethral stricture repair. Urology 2004; 64:648-650.

60 Palminteri E, Lazzeri M, Guazzoni G, Turini D, Barbagli G: New 2-stage buccal mucosal graft urethroplasty. J Urol 2002;167:130132.

-61 Markiewicz MR, Lukose MA, Margarone JE 3rd, Barbagli G, Miller KS, Chuang SK: The oral mucosa graft: a systematic review. J Urol 2007;178:387-394.
62 Andrich DE, Greenwell TJ, Mundy AR: The problems of penile urethroplasty with particular reference to 2-stage reconstructions. J Urol 2003;170:87-89.

63 Barbagli G, De Angelis M, Palminteri E, Lazzeri M: Failed hypospadias repair presenting in adults. Eur Urol 2006;49:887-894.

64 Barbagli G, Lazzeri M, Palminteri E, Turini D: Lichen sclerosis of male genitalia involving anterior urethra. Lancet 1999;354:429.

65 Dubey D, Sehgal A, Srivastava A, Mandhani A, Kapoor R, Kumar A: Buccal mucosal urethroplasty for balanitis xerotica obliterans related urethral strictures: the outcome of 1 and 2-stage techniques. J Urol 2005;173:463466.

66 Trivedi S, Kumar A, Goyal NK, Dwivedi US, Singh PB: Urethral reconstruction in balanitis xerotica obliterans. Urol Int 2008;81:285289.

67 Kulkarni S, Barbagli G, Kirpekar D, Mirri F, Lazzeri M: Lichen sclerosus of the male genitalia and urethra: surgical options and results in a multicenter international experience with 215 patients. Eur Urol 2009;55 945-956.

68 Peterson AC, Palminteri E, Lazzeri M, Guanzoni G, Barbagli G, Webster GD: Heroic measures may not always be justified in extensive urethral stricture due to lichen sclerosus (balanitis xerotica obliterans) Urology 2004;64:565-568.

69 Carney KJ, McAninch JW: Penile circular fasciocutaneous flaps to reconstruct complex anterior urethral strictures. Urol Clin North Am 2002;29:397-409.

70 Hick EJ, Morey AF: Initial experience with fibrin sealantin pendulous urethral reconstruction. Is early catheter removal possible? J Urol 2004;171:1547-1549.

71 Barbagli G, De Stefani S, Sighinolfi MC, Annino F, Micali S, Bianchi G: Bulbar urethroplasty with dorsal onlay buccal mucosal graft and fibrin glue. Eur Urol 2006;50:467474 .
72 Barbagli G, De Stefani S, Sighinolfi MC, Pollastri CA, Annino F, Micali S, et al: Experience with fibrin glue in bulbar urethral reconstruction using dorsal buccal mucosa graft. Urology 2006;67:830-832.

73 Villavicencio Mavrich H, Moreno RP, Sariol JC, Briones JR, Bordes AR, Rodríguez JV: Experience with lyophilized human dura mater for urethral strictures. J Urol 1998; 160:1310-1311.

74 Carson CC: Urethroplasty: a model for international progress in urology. Contemp Urol 2006;18:11.

75 Palminteri E, Berdondini E, Colombo F, Austoni E: Small intestinal submucosa (SIS) graft urethroplasty: short-term results. Eur Urol 2007;51:1695-1701.

76 El Kassaby AW, Retik AB, Yoo JJ, Atala A: Urethral stricture repair with an off-theshelf collagen matrix. J Urol 2003;169:170173.

77 El Kassaby A, AbouShwareb T, Atala A: Randomized comparative study between buccal mucosal and acellular bladder matrix grafts in complex anterior urethral strictures. J Urol 2008;179:1432-1436.

78 Bhargava S, Patterson JM, Inman RD, MacNeil S, Chapple CR: Tissue-engineered buccal mucosa urethroplasty - clinical outcomes. Eur Urol 2008;53:1263-1269.

79 Naude JH: Endoscopic skin-graft urethroplasty. World J Urol 1998;16:171-174.

80 Farahat YA, Elbahnasy AM, El-Gamal OM, Ramadan AR, El-Abd SA, Taha MR: Endoscopic urethroplasty using small intestinal submucosal patch in cases of recurrent urethral stricture: a preliminary study. J Endourol 2009;23:2001-2005.

81 Bhargava S, Chapple CR, Bullock AJ: Tissueengineered buccal mucosa for substitution urethroplasty. BJU Int 2004;93:807-811.

82 Chen F, Yoo JJ, Atala A: Experimental and clinical experience using tissue regeneration for urethral reconstruction. World J Urol 2000;18:67-70. 